\title{
Shop rental growth assessments
}

Received: 28 August 2003

\section{Edmund Camerer Cuss}

is a director of the Property Information Project and is a consultant, in different roles, to both Donaldsons and Savills Fund Management. He is a board member of the Royal Institution of Chartered Surveyors' Commercial Property Faculty and a committee member of the Society of Property Researchers. The views expressed are entirely his own.

\begin{abstract}
This paper outlines the author's contention that investors, valuers and others are placing undue reliance on certain retail market data. It examines aspects of a practical difficulty that arise in consequence - the business of implicitly or explicitly assessing rental growth rates for individual retail properties.
\end{abstract}

\section{Keywords:}

supply, demand, town size, town wealth, change, filtering

\section{RETAIL IS DIFFERENT}

It is a reasonable working assumption that what is good for occupiers is also good for investors and developers. The general rule - to which there are plenty of exceptions - is that if the investor/developer goes where the demand is, and the building is suitable for the demand, he will not be far wrong.

In most spheres, occupiers are masters of their destiny in the sense that they have known inputs to the decision-making process of where they locate, whether the inputs are client bases, suppliers, workforce, patients or transport interchanges. But one set of occupiers are less in charge of their destiny than most. They depend on other people's judgment almost entirely in respect of where they locate and are at the mercy of these third parties. They do not have a known client base but thousands of potential clients who may or may not use their services; they assume that an unknown proportion will approve their choice of location. These unusual occupiers are retailers, of course, who are slaves to their consumer customers. The average punter is unpredictable, disloyal, demanding, nameless and also invisible and ever changing.

It is only retail property that brings this relationship to property location choices. Shops exist for the precise purpose of 'interacting' with unknown customers, quite unlike office, warehouse or industrial property that can be where occupiers choose. There are other properties besides shops that exist for use by third parties, such as schools and hospitals, but within reason these are destinations in their own right and do not need to pander to their 


\section{Supply}

Demand

be where the wallets and purses are going to be, where the 'urban grazing' is done.

There are some very sophisticated approaches now available to help retailers locate where they will do best, beyond the simple gravity-modelled catchments. Then there is customer profiling, loyalty cards and a host of modern techniques to assist them to market themselves once they are in place. The British consumer has been analysed, every which way, by dozens of well-known and lesser-known marketing and location experts. There is footfall to count, basket size to measure, cars to log and the whole science of product display, quite apart from inventory, restocking and automatic ordering.

\section{RETAIL DEMAND AND SUPPLY}

Although rent levels in all the property sectors are the result of supply and demand, they interact differently in each property type. Town-centre retail is unusual for the following reasons.

- Overall in-town shop supply is much more fixed, much more tightly drawn, than other property classes. Supply is defined absolutely by location, and significant changes in net total provision are few, well heralded and slow to appear. In parallel with that, individual shop availability is handled less openly than in other agency markets, so that reliable availability data are very hard to secure. Investors (and one must add their valuers) do not have the time or information sources to assess towncentre individual retail availability when judging a town-centre shop, in the way they might for offices or industrials.

- The concept of prime pitch is pretty much limited to retail. One takes that for granted, but one needs to remember that shop property is selected largely on its locational ability to attract consumers, unlike other property types where access is important but less crucial. This is broadly true even for destination retailers.

- Retailers will often assess how much rent they can afford to pay for a particular size of unit in a centre. Very few office or industrial occupiers can make that assessment, and they will mainly work off what they are willing to pay.

- Like shop supply, shop demand is also much more fixed in the sense that most retailers are carefully focused. If they want central Richmond one does not offer them Isleworth, nor Leith rather than Edinburgh. If the right shape, size and pitch of unit is not available in Richmond, the retailer may defer his requirement altogether.

- Towns and locations compete, however. It is clear that not only do improved access and additional supply assist one centre against another but also that a growing band of retailers have in the last few years shown increased ambivalence as to whether they are in town or out of town. 
Location

\section{Influences}

- Towns have fashion cycles, unlike other sectors. If two or three traders open in what had until then been an unconsidered centre, others follow quickly. The reverse is true: if a centre loses some key traders, the flag goes up for others as well. The author can offer no clear proof, but it seems to be true that low relative demand for units in a town denotes increasing, but usually unseen, individual availability and strong demand indicates a drop in potential availability.

\section{THE INVESTOR PERSPECTIVE}

These differences in the retail market make it worthwhile to look at the location issue from the investors' perspective. For simplicity, assume a hypothetical investor in town-centre shops and shopping centres. Assume they are property cognate long-term investors of their own money, rather than just the bank's, and want something other than bond-like holdings. Such a player is riding on the back of the retailers, hoping they have got it right, not necessarily one by one but en masse. He hopes that the locations they prefer really are the right ones, because he wants them to trade well and make good profits so as to afford his growing rental expectations. His principal concern is rental growth. He will be paying a yield that implicitly or explicitly assumes a rental growth rate. How will he or his advisers choose it?

This hypothetical investor and his valuer should both be aware that the local level of in-town retail rental growth is much more heavily dependent on changes in demand than it is on supply other things being equal, such as no sizeable new schemes. But now consider what the investor or valuer actually do. They bone up on new floorspace provision and competing locations. Most are used to a diet that includes data on town size, wealth and socioeconomic issues, and catchment population statistics, and frequently these are included in descriptive particulars. Demand data are almost nowhere to be seen.

The standard toolkit is in truth really designed for those advising individual developers and individual retailers, with their different focus, rather than investors. The data influence individual retailers, and so they may impact on longer-term retailer demand in any single town centre. They could then feed through into a rental bid that does subsequently impact on the rental market. Yet they are precise to each trader's product offer and market segment, and the investor is interested only in the 'bulked up' answers of many retailers, in the result of a multiplicity of rental bids. Furthermore, the measures highlighted are indirect; investors and valuers will be looking at them only to try to second guess what the individual reactions to them are likely to be from a multiplicity of unspecified retailers. Additionally, they are longer-term measures; they do not speak of the situation on the ground today. Finally, when the investor or valuer considers the result, from the multiplicity of assumed reactions, he is better informed, for sure, but he is 
probably none the wiser as to the immediate future of rental growth in that centre.

\section{Town size}

There is a widespread belief that larger centres produce better rental growth. Nonetheless, whether one judges town size by turnover, by catchment population, by retail offer, by Zone A levels or by retail hierarchy, this is not the case now, even if it once was. There will be good reasons for investors to rate larger centres at a lower yield, but the rental value growth $(\mathrm{RVG})$ rate is not one of them (Figure 1).

Catchment population (gravity model)

Retail offer (count of top 250 traders)

Town size

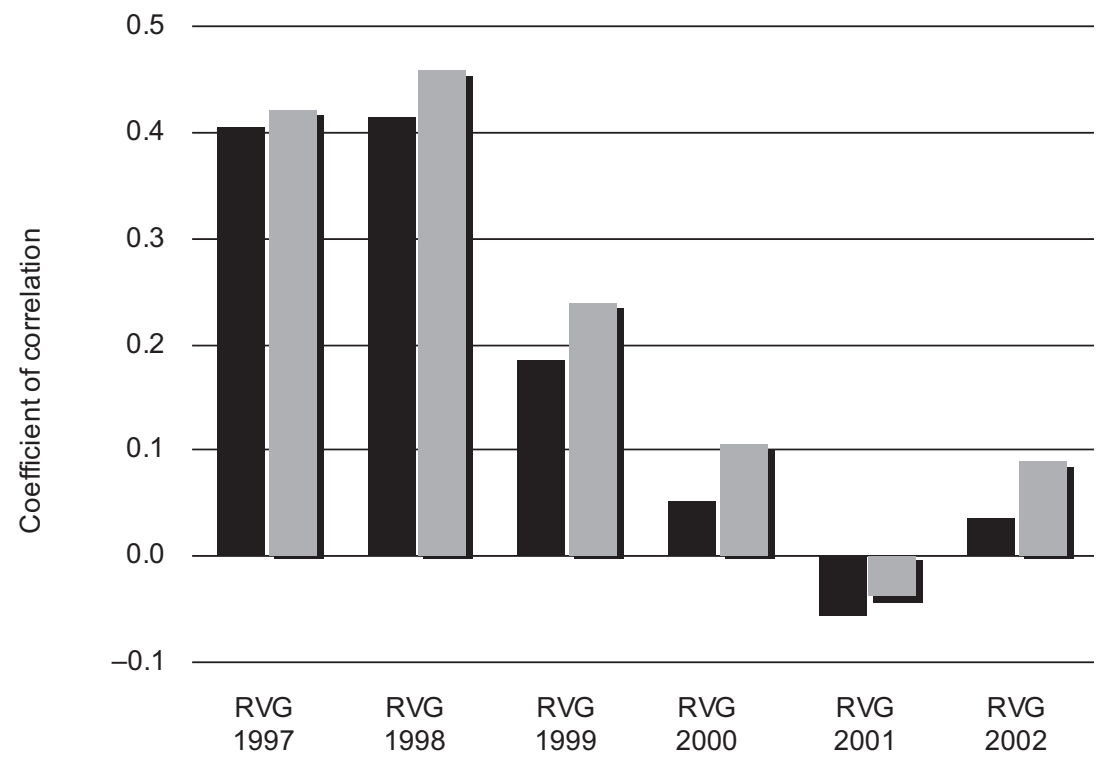

Figure 1: Shop rental growth and centre size

Source: Retail Locations, CACl Investment Property Database (IPD)

\section{Local wealth}

There are no data to indicate that rental growth is better, over time, in upscale rather than downscale locations. Income per capita is not directly relevant to the local performance of rents. Some investors may feel more comfortable in historic cathedral or 'carriage trade' centres, but there is no linkage between shop rental growth and socio-economic groups (Figure 2).

\section{WHY THE DATA ARE FRAGILE}

It is not surprising that the links between rental growth, town size and wealth are rather weak. Over time, current Zone A rents in a town come to reflect the trading potential of that town. Its rent 


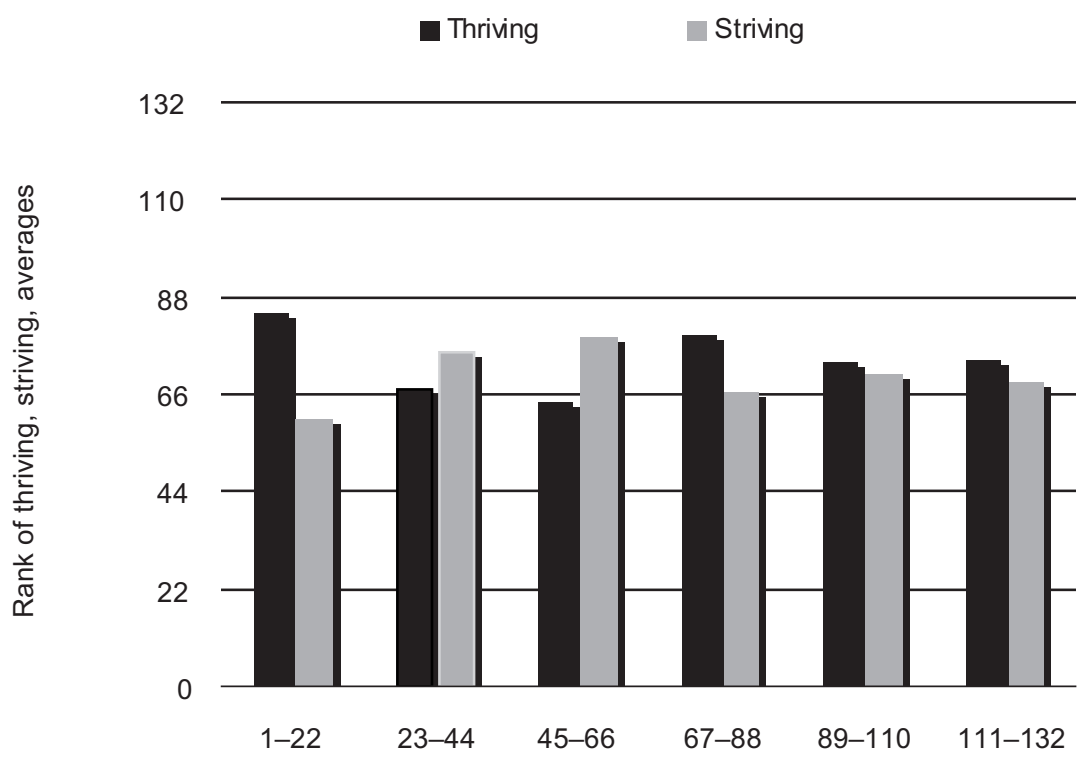

132 centres ranked by rental growth, in sets of 22

Figure 2: Shop rental growth and wealth

Source: $\mathrm{CACl}$ and IPD

Status quo

\section{Change}

levels accommodate its retail offer and its shoppers' current spending power. These factors are useful to retailers in assessing their own customer base locally, and they may help others to guess at retailer profitability. But for them to be of significant help in judging future rental growth, one would want to be able to forecast the change in local car ownership, or whatever, as being above or below average. If one thinks of two different towns with nearidentical rental growth, such as workaday St Helens and affluent Canterbury, one could not have forecast that similarity from the absolute number of blue-collar workers or income per capita locally, say three years ago.

Rent levels reflect shoppers' spending power. But knowing about spending power does not help in assessing rental change, and it is change that the investor or valuer is seeking to pin down. What would drive changes in rental values are changes in spending power, and it is only changes in the data that will assist them changes in the number of cars per household in a catchment, or whatever. To be useful, one would need to be able to forecast local car ownership changes as being a certain degree above or below average. Absolute levels, quite naturally enough, tend only to explain why rents are where they are now.

There is a further disadvantage. More cars in St Helens may be an indicator of more spending, or it could mean less because shoppers would find it convenient to drive into Liverpool. One has always to be careful about assuming direct cause and effect. 


\section{Direct/Indirect}

\section{Limitations}


and industrial sectors - then if one multiplies such company requirements by 100 retailers, individual centres can be usefully compared. The objective is a demand series that gives valuable regular output, with both national and local-level results, with the aim of augmenting current information sources. It is essential to acknowledge the practical limitations of collating reliable demand data, and to avoid writing a recipe for the (unattainable) ideal. Once again, the limitations need to be recognised.

The initial requirement is to convert existing retail agency demand information into appropriate and usable data. Existing information is collated for broking and listings purposes, whereas investment and valuation teams require, crucially, something else. The most comprehensive independent demand monitoring service, which had been running for a decade, was found to be Retail Focus. On request, it has been producing a bespoke series of quarterly filtered demand information that accounts for the following.

- Rental growth in a centre is chiefly established in the best pitches, and it is demand for strong locations that one needs to isolate. Space in peripheral locations inflates totals of space demanded in any one centre but does not have any positive impact on Zone A rent levels. Kwik Fit may want 12,000 sq ft but that does nothing for core area rental growth. Using the

\section{Filtering} requirements of the 250 or so leading retail fascias that seek prime or good secondary pitches isolates the necessary demand.

- One needs to eliminate those requirements that add to the figures but do not affect rent levels - franchises and large stores. For example, while demand from Harvey Nichols had a large impact on the amount of space demanded in Leeds, its effect on rental Zone A via comparables was negligible. It acted as an attractor for unit operators, but that is separately measured.

- There is the need to filter out incongruities, such as identical demand information originating from different sources, and the need to keep pace with the constantly changing fascia names, consolidations and new market entrants. The survey depends on retailer and agency participation in the constant proactive updating of requirements. Currently, there is a 68 per cent level of participation, with demand from just under half at present. The energy with which the collation task is undertaken is plainly important to the output.

- It is necessary to adjust the 'raw' agency data to account for the rent pressures arising from the number of requirements that exist as opposed to the simple total of floorspace sought. About 50 per cent of the space that is sought is down to the 80 per cent of requirements that are for less than 4,000 sq ft of trading area. A multiplicity of small demands is likely to influence rent levels more than a few large demands. Useful demand data therefore entail weighting the number of requirements and the total of space required, in different size ranges. The weightings can be 


\section{Affordability}

Profitability tuned from studies of past data, and have perforce to assume that all centres respond identically, although this is not strictly true.

The national results of this study have been circulating for the past year (see www.thepip.com). Beneath that, demand data for 250 locations are monitored and compared with the retail offer, catchment population, pedestrian flowcount and past rental growth from Retail Locations, CACI, Professional Marketing Research Society (PMRS) and the Investment Property Databank (IPD) respectively, both current and historic, which all goes to create an enhanced information and forecasting tool. With demand proving rather more reliable than other series, it combines well with them to form a weighted centre guide. But there remains the principal hurdle of specified demand being targeted at centres that are not 'affordable' by the retailer, meaning that his demand is not actually effective in any bidding process. It appears that recently this problem has increased.

This portion of demand, which is ineffective, could have been expected to increase given the national picture shown in Figure 3. Consumers are becoming increasingly value conscious, and no longer expect prices to rise but now look for reducing prices. Retailer profitability is an important consideration in setting up an expansion policy. When overheads are under pressure, expansion will be to secure volume growth because margins are slim, or expansion will be deferred under a cautious 'wait and see' policy. Either way, the result is pretty negative for rental growth; it will be limited to low rental bids that do not promote rental growth, or will not exist at all.

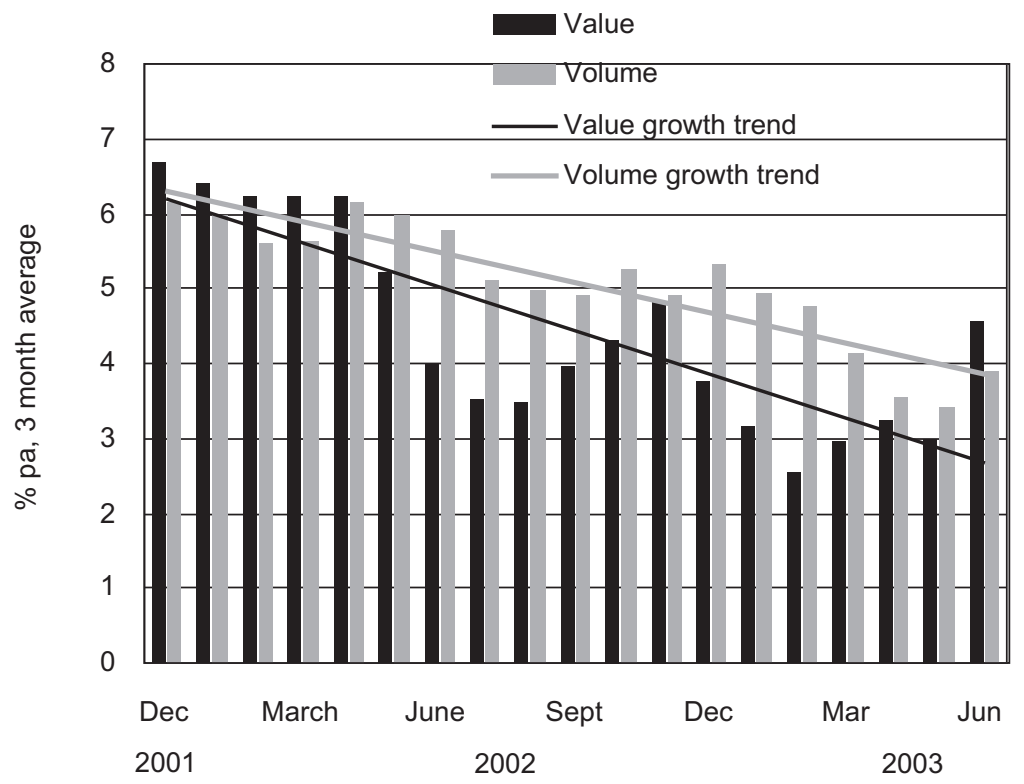

Figure 3: Sales growth

Source: Office for National Statistics 
Old beliefs

\section{Distribution}

What is known about the results of those choices on expansion? The demand study referred to shows that there has indeed been a fall in demand, led by the larger space users. There have been a number of corporate retailer failures and retrenchments, and some high-profile consolidations, although it seems that the bottom of the demand trough may have been reached. There is also some evidence that rental growth in in-town retailing has also passed the bottom of its cycle, although few are banking on that just yet.

Demand will become an increasingly valuable measure for rental growth assessment, but for the reasons given in the current market it still lacks authoritative explanatory power, and its historic run of data is too short. At the same time and for some of the same reasons, the socio-economic and demographic data are not able to cope with the current retailing climate. Indeed, the correlation between the last three years' annualised rental value growth, the size of the retail offer and the catchment population is very weak indeed, although this was not always so, as Figure 1 shows. The disappearance of some of the old beliefs has led to much private discussion among advisers and researchers, albeit they have not come to any solid conclusions. This is one of the realisations that have reinforced the need for the demand study that has been mentioned.

\section{RENTAL GROWTH}

Going back to the hypothetical investor or valuer, how is he to choose his rental growth rate? As the industry moves towards discounted cash flow valuation approaches and becomes more adept at breaking down all-risks comparable yields, this will become more relevant. Aside from growth rate volatilities above and below the average each year and variations from one year to the next (the beta coefficient and standard deviations), in normal parlance how close must one's assessment be to be useful, and over what period? Maybe getting the central result correct is sufficient so long as one is not being called upon to differentiate one centre from another, but usually that differentiation is exactly what is required.

The range and distribution of in-town shop rental growth performance is broadly repetitive year by year. Figure 4 shows the 1999-2002 results. The range from best to worst was 14.2 per cent, with the maximum shown on the right and the minimum on the left. One can see how the middle two quartiles are concertinaed, covering the growth rates of the central 50 per cent of centres nearly 100 towns here.

\section{ARE ASSESSMENTS EFFICIENT?}

Not many investors or valuers regularly check back on their threeyear forward estimates and can tell one their success rate. In practice, few have any town-by-town forecasts, the main hurdles being time, cost and only sporadic need. The assessments have to be prepared in advance to be of real value, and made across the full 


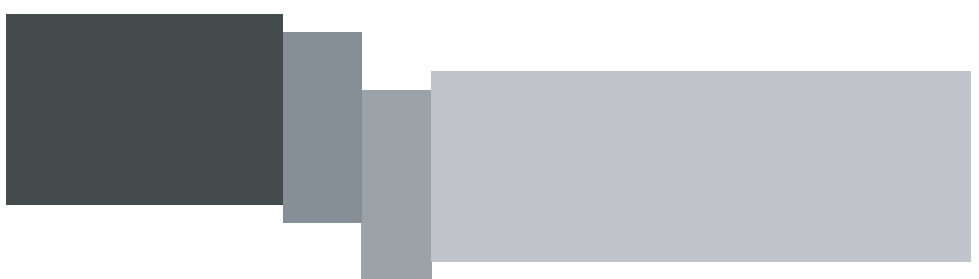

$\begin{array}{lrlrr}\text { Maximum } & 11.7 \% & \text { Range } & \text { 25th-75th percentile } & 2.6 \% \\ \text { 25th percentile } & 3.5 \% & & & \\ 75 \text { th percentile } & 0.9 \% & \text { Range } & \text { 1st-100th percentile } & 14.2 \% \\ \text { Minimum } & -2 . \% & & \end{array}$

Figure 4: Annualised shop rental growth range, 1999-2002

Source: IPD

range of locations. There are ways in which the assessments might be done which would be prohibitively expensive on this basis. For valuers, the issue is the overhead cost of keeping such assessments going, and for all but the largest investors and advisers the same applies; cost is only justified for a major investment where the likelihood of the deal being abortive is small. For these reasons, assessments are likely to be brought in from specialist providers necessarily independent - who will soon let one know if at low cost they are making regular assessments successfully enough to impact on performance.

The present state of affairs is somewhat unsatisfactory, in that many rental growth judgments at the local area level are currently tied to the use of data that have limited usefulness, and low predictive power. The market is focused currently on leverage as much as on rental growth, which masks the difficulty. Recognising

\section{Prediction} the weaknesses and seeking more sophisticated tools is the first step, but the author concludes by suggesting that the property research community may lack the will and the financial backing and be too fragmented to succeed at present in producing a costeffective market-wide tool. The hypothetical investor and valuer, then, are left to their own devices by a strategy of seeming inactivity. 